with what appeared to be simpler device positioning and implantation relative to the transfemoral approach. A patent left internal thoracic artery graft is probably a contraindication to a left axillary approach. The potential to compromise innominate artery flow is a relative contraindication to the right axillary approach.

The trans-axillary artery approach offers an additional tool in the new armamentarium for the treatment of aortic stenosis in patients who are candidates for TAVI but who have significant respiratory dysfunction and problematic iliofemoral access precluding the other available techniques. We also believe that it offers some advantages relative to the transfemoral and transapical approaches and is worthy of evaluation in a broader patient population as an alternative access route.

\section{References}

1. Webb JG, Chandavimol M, Thompson C, Ricci DR, Carere R, Munt B, et al. Percutaneous aortic valve implantation retrograde from the femoral artery. Circulation. 2006;113:842-50.

2. Ye J, Cheung A, Lichtenstein SV, Pasupati S, Carere RG, Thompson CR, et al. Six-month outcome of transapical transcatheter aortic valve implantation in the initial seven patients. Eur J Cardiothorac Surg. 2007;31: $16-21$.

3. Grube E, Schuler G, Buellesfeld L, Gerckens U, Linke A, Wenaweser P, et al. Percutaneous aortic valve replacement for severe aortic stenosis in high-risk patients using the second- and current third-generation self-expanding CoreValve prosthesis: device success and 30-day clinical outcome. J Am Coll Cardiol. 2007;50:69-76

4. Cribier A, Eltchaninoff H, Tron C, Bauer F, Agatiello C, Sebagh L, et al. Early experience with percutaneous transcatheter implantation of heart valve prosthesis for the treatment of end-stage inoperable patients with calcific aortic stenosis. $J A m$ Coll Cardiol. 2004;43:698-703.

5. Webb JG, Pasupati S, Humphries K, Thompson C, Altwegg L, Moss R, et al. Percutaneous transarterial aortic valve replacement in selected high-risk patients with aortic stenosis. Circulation. 2007;116:755-63.

\title{
Palliative bidirectional Glenn anastomosis for unresectable metastasis in the right ventricle from renal cell carcinoma 16 years after nephrectomy
}

\author{
Naoto Morimoto, MD, Keisuke Morimoto, MD, Yoshihisa Morimoto, MD, Toshihito Sakamoto, MD, Akiko Tanaka, MD, \\ Masamichi Matsumori, MD, Kenji Okada, MD, and Yutaka Okita, MD, Kobe, Japan
}

We report a patient with late renal cell carcinoma metastasis to the right ventricle 17 years after radical nephrectomy. The unresectable huge metastasis caused hemodynamic impairment due to right ventricular inflow and outflow tract obstruction, which was managed by means of partial excision of right ventricular intracavity tumor, tricuspid valve replacement, and bidirectional cavopulmonary anastomosis.

\section{CLINICAL SUMMARY}

A 53-year-old woman was admitted in a local hospital because of right-heart failure, including 2-month-old palpitation and dyspnea on exertion. Seventeen years earlier, she had undergone right nephrectomy for a high-grade (G3) clear cell-type renal cell carcinoma (RCC) (pT1 bN0 M0). Echocardiography showed that the massive right ventricular intracavity mass obliterated the right ventricular cavity. Pericardial effusion was massive and drawn off by pericardio-

\footnotetext{
From the Division of Cardiovascular Surgery, Kobe University Graduate School of Medicine, Kobe, Japan.

Received for publication Dec 18, 2007; accepted for publication Dec 24, 2007.

Address for reprints: Naoto Morimoto, MD, 7-5-2, Kusunoki-cho, Chuo-ku, Kobe,

Japan (E-mail: naotom@med.kobe-u.ac.jp).

J Thorac Cardiovasc Surg 2009;137:775-7

$0022-5223 / \$ 36.00$

Copyright (c) 2009 by The American Association for Thoracic Surgery

doi:10.1016/j.jtcvs.2007.12.089
}

centesis. The diagnosis of metastatic RCC was made from biopsy. The patient was referred to us for further investigations and treatment.

Echocardiography and magnetic resonance imaging revealed a large mass that nearly obliterated the right ventricular cavity and that invaded into the ventricular septum. The septum was remarkably hypertrophied up to $29 \mathrm{~mm}$, compressing the left ventricular cavity. The intracavity mass also involved right ventricular free wall and subvalvular apparatus of tricuspid valve, extending into left ventricular wall across around the apex (Figure 1). A systolic right ventricular pressure was elevated to $55 \mathrm{~mm} \mathrm{Hg}$.

After admission, the patient deteriorated despite inotropic support. Six days after admission, she developed low urine output and orthopnea. Blood chemistry analysis showed acute liver dysfunction and coagulopathy disorder. Uncontrollable heart failure necessitated percutaneous cardiopulmonary support and emergency surgery.

Midsternotomy imaging revealed that the intramural tumor mass occupied not only the entire anterior and diaphragmatic free wall of the right ventricle but also the apical wall of the left ventricle. After cardioplegic arrest, the infundibular portion of the right ventricle was incised longitudinally. The entire right ventricular cavity was filled with fragile yellow-gray tumor, which had a stalk growing from the 


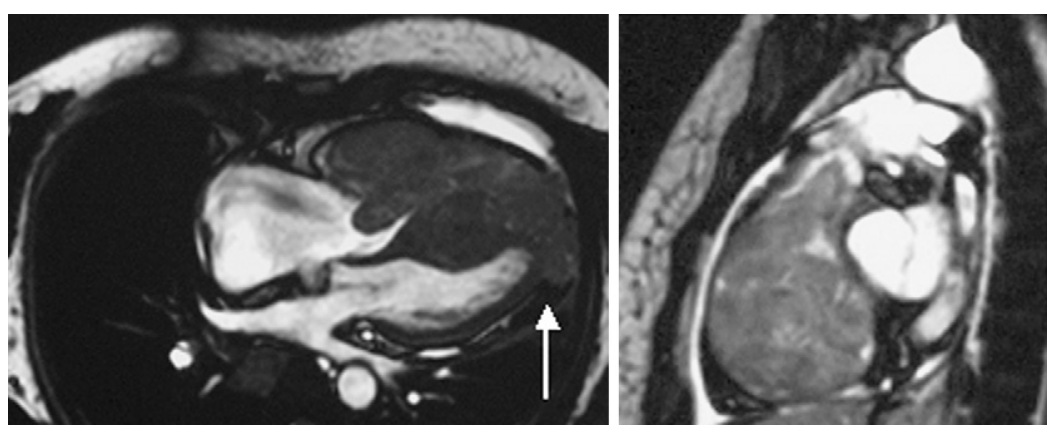

FIGURE 1. Preoperative magnetic resonance images revealed right ventricular intracavity mass with nearly obliterated right ventricle and right ventricular outflow tract. The ventricular septum was thickened and the tumor was invading into the apical part of left ventricle (arrow).
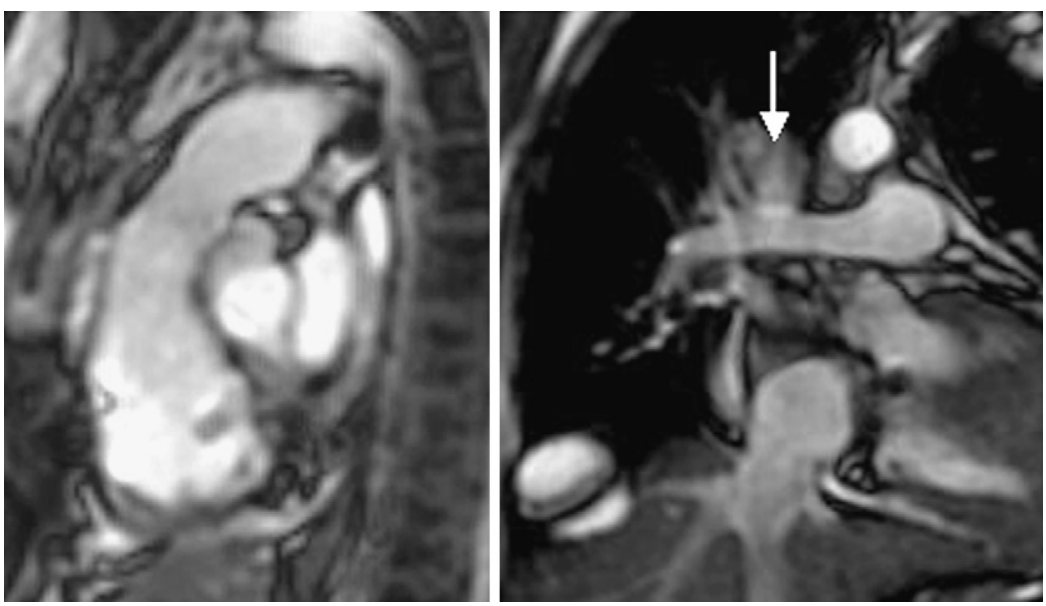

FIGURE 2. Postoperative magnetic resonance images showed patent cavopulmonary shunt (arrow) and relief of right ventricular obstruction.

intraventricular septum. The involvement of the septum and part of left ventricle precluded complete resection of the tumor. To relieve intra-right ventricular obstruction, we removed as much of the intracavity mass as possible from right atriotomy and right ventricular infundibular incision. A 27-mm Mosaic porcine bioprosthesis (Medtronic Inc, Minneapolis, Minn) was implanted into tricuspid position because of an embroiled subvalvular apparatus. After declamping the aorta, bidirectional Glenn anastomosis was created to ensure pulmonary blood flow when the growth of residual tumor would cause recurrent obstruction in the future. The patient was weaned from cardiopulmonary bypass without difficulty.

The patient's postoperative course was characterized by remarkable recovery. Postoperative magnetic resonance image showed patent bidirectional Glenn anastomosis and relief of right ventricular obstruction (Figure 2). Histologic examination of the resected tumor was compatible to metastatic renal cell carcinoma. At present, 5 months after surgery, the patient is free from heart failure and received adjuvant immune therapy.

\section{DISCUSSION}

RCC is the most common malignancy of the kidney. One third of patients who have nephrectomy for localized RCC have a lifelong risk of recurrence because RCC is biologically slow growing. However, late cardiac metastasis of $\mathrm{RCC}$ is rare. We found only 3 case reports about late cardiac metastasis in the literature. ${ }^{1-3}$ Intervals from nephrectomy to presentation of the recurrence were 4,6 , and 20 years, respectively.

Partial resection of obstructing primary cardiac neoplasm may be a lifesaving procedure when the tumors are benign. Resection of the cardiac metastasis can improve survival in a select group of patients whose primary tumor is well controlled. As for pulmonary artery sarcoma with hemodynamic impairment, Kruger and colleagues ${ }^{4}$ reported that the average survival time of a nonoperated group was 1.5 months, whereas that of an operated group was 10 months.

An additional bidirectional Glenn anastomosis was performed to ensure pulmonary blood flow if the mass obliterated the right ventricle in the future, as well as to guard against right ventricular failure due to the incomplete 
resection. Beghetti and associates ${ }^{5}$ reported that palliative superior cavopulmonary anastomosis was effective and functioned well for 2 years in a patient with huge right ventricular fibroma. As for methodology of superior cavopulmonary anastomosis, bidirectional Glenn anastomosis is preferred to hemi-Fontan procedure because the superior vena cava should be disconnected from the right atrium to guard cavopulmonary anastomosis against tumor extension into the right atrium or right atrial thrombus secondary to right ventricular obstruction.

Although surgical excision does not cure the primary disease in metastatic tumors of the heart, palliative resection may be justified for immediate life-threatening danger due to an intracavity space-occupying lesion. Additional bidirec- tional cavopulmonary anastomosis may provide assurance in long-term pulmonary blood flow in unresectable cardiac metastasis.

\section{References}

1. Brandley SM, Bolling SF. Late renal cell carcinoma metastasis to the left ventricular outflow tract. Ann Thorac Surg. 1995;60:204-6.

2. Roigas J, Schroeder J, Rudolph B, Schnorr D. Renal cell cancer with a symptomatic heart metastasis. Br J Urol. 2002;90:622-3.

3. Sobue T, Iwase M, Aoki T, Noda A, Tanaka M. Solitary left ventricular metastasis of renal cell carcinoma. Am Heart J. 1993;125:1801-2.

4. Kruger I, Borowski A, Horst M, Vivie ER, Theissen P, Gross-Fengels W. Symptoms, diagnosis, and therapy of primary sarcomas of the pulmonary artery. Thorac Cardiovasc Surg. 1990;38:91-5.

5. Beghetti M, Haney I, Williams WG, Mawson J, Freedom RM. Massive right ventricular fibroma treated with partial resection and a cavopulmonary shunt. Ann Thorac Surg. 1996;62:882-4.

\section{Repair for acute type A aortic dissection with a long elephant trunk technique}

Hiroki Hata, MD, PhD, Koichi Toda, MD, PhD, Yasuhiro Shudo, MD, Satoshi Kainuma, MD, Kiyoshi Yoshida, CE, Keiji Yamamoto, CE, and Kazuhiro Taniguchi, MD, PhD, Sakai, Japan

Total arch replacement (TAR) is often performed for acute type A aortic dissection (AAAD) involving the aortic arch. ${ }^{1}$ However, because conventional TAR including the use of a short elephant trunk ${ }^{2,3}$ requires careful dissection of the surrounding tissue and elaborate distal anastomosis at the site of dissection and occasionally at the site of the aneurysm, there could be some cases in which bleeding is uncontrollable or circulatory arrest time is prolonged. To reduce such problems, we applied TAR with distal anastomosis just proximal to the innominate artery using a long elephant trunk (LET) technique, which we $\mathrm{e}^{4,5}$ have introduced for true arch aneurysms and chronic aortic dissections.

\section{CLINICAL SUMMARY}

Four consecutive patients with AAAD (3 men) underwent surgical repair, from March 2006 to January 2007, with TAR using the LET technique. The mean age was 62 years (range, 51-71 years). Preoperative computed tomography (CT) and transesophageal echocardiography revealed that in all cases

\footnotetext{
From the Department of Cardiovascular Surgery and Clinical Engineering Section, Japan Labour Health and Welfare Organization, Osaka Rosai Hospital, Sakai, Japan. Received for publication Dec 18, 2007; revisions received June 13, 2008; accepted for publication July 6, 2008.

Address for reprints: Kazuhiro Taniguchi, MD, PhD; 1179-3, Nagasone-cho, Kita-ku, 591-8025 Sakai, Japan (E-mail: hatahiro1019@yahoo.co.jp).

J Thorac Cardiovasc Surg 2009;137:777-8

0022-5223/\$36.00

Copyright (C) 2009 by The American Association for Thoracic Surgery

doi:10.1016/j.jtcvs.2008.07.058
}

the entry site was located in the ascending aorta near the innominate artery. All cases were DeBakey type I. There were not any dissection-related complications.

TAR using a 4-branched Hemashield arch graft (Hemashield Platinum, Woven Double Velour; Boston Scientific, Wayne, NJ) was done through a median sternotomy, similar to previously reported methods. ${ }^{4}$ In brief, after minimal dissection of the ascending aorta and arch vessels, extracorporeal circulation was established with bicaval venous drainage and a right axillary artery return via an anastomosed 8-mm graft. After cardiac arrest with retrograde cold blood cardioplegia, the ascending aorta was transected above the sinotubular junction and a minimal amount of gelatinresorcin-formalin glue was used in the proximal false lumen. After placement of a running suture in the aortic edge to fix the intima tightly, an appropriately sized 4-branched graft was anastomosed with interrupted pledget-supported sutures and an additional running suture. Then, under moderately hypothermic $\left(25^{\circ} \mathrm{C}\right)$ circulatory arrest with antegrade selective cerebral perfusion, ${ }^{4}$ the ascending aorta was declamped and the LET was pulled into the true lumen of the dissected aorta with a catching catheter (Amplatz Goose-Neck Snare; ev3 Inc, Plymouth, Minn) that was introduced from the true lumen of the femoral artery (Figure 1, $A$ ). Next, an open distal anastomosis was performed at the base of the innominate artery without glue and reinforced with a felt strip (Figure 1,B). Antegrade systemic perfusion was resumed through the 